\title{
REFLECTIONS ON THE INDOOR ENVIRONMENTAL MONITORING SYSTEM OF THE HERITAGE BUILDINGS IN THE PALACE MUSEUM — A CASE STUDY OF THE MERIDIAN GATE EXHIBITION HALL
}

\author{
Xincheng Zhang ${ }^{\mathrm{a}}$, Peilin Daib ${ }^{\mathrm{b}}$ Ze Zhao ${ }^{\mathrm{c}}$ \\ ${ }^{a}$ Department of Architectural Heritage, the Palace Museum, Beijing 100009 \\ ${ }^{b}$ Beijing Zhongketianhe Technology Co., Ltd, Beijing 100190 \\ ${ }^{c}$ Institute of computing, Chinese Academy of Sciences, Beijing 100190, China
}

KEY WORDS: The Forbidden City; World Cultural Heritage; Indoor Micro-Environment Monitoring; LoRa; Historic Buildings; Visitor Volumes

\begin{abstract}
:
The indoor micro-environment monitoring system of the Forbidden City aims to explore the thresholds of environmental indicators under the presence of coexistence of multiple cultural relics through the analysis of environmental monitoring data and the deterioration of cultural heritiges, and to develop the optimal strategies for the protection and utilization of cultural heritiges. The objects of interest include historic buildings with modernised interior or those used for the storage of movable cultural relics. Several environmental indicators are employed to quantify the dynamic changes of the indoor environment. In order to meet the requirements of 24-hour data collection, real-time data transmission, and easy management and maintenance, the indoor micro-environmental monitoring system has been continuously upgraded and the "LoRa-based Hybrid Self-Organising Network System Deployment Solution" was deployed to satisfy the demands of high precision, low energy consumption, constant stability, and low cost. Taking the Meridian Gate exhibition hall of the Forbidden City during the exhibition "Splendor Forever: Six Centuries of the Forbidden City" as an example, we discussed the relationship between temperature, humidity, carbon dioxide $\left(\mathrm{CO}_{2}\right)$ concentrations and visitor volumes, and the results provide a basis for optimizing the management of the exhibition. Future improvements to the indoor environment monitoring should focus on strengthening the in-depth mining of data and multi-factor correlation analysis, so as to gradually form a systematic and comprehensive monitoring management system.
\end{abstract}

\section{INTRODUCTION}

\subsection{Backgrand}

The Forbidden City was the royal palace of the Ming and Qing dynasties, which has a history of 600 years so far. As one of the world's largest and best-preserved wooden structures, the Forbidden City is undoubtedly an invaluable architectural treasure of mankind. However, after 600 years of environmental erosion, the historic buildings of the Forbidden City have suffered varying degree of deterioration to different and are in urgent need of scientific conservation to slow down their aging and decay. The scientific protection cannot be do without the data support provided by monitoring.

The impact of the environment on historic buildings is subtle, unavoidable and irreversible, which requires long-term effective monitoring of environmental factors and using monitoring data benefits policy-making processes. The monitoring of environmental factors in the Forbidden City can be divided into four levels: peripheral environment monitoring, outdoor environment monitoring, indoor microenvironment monitoring, and typical problems monitoring (Figure 1). Due to its dual identity as a World Heritage Site and a museum, the Forbidden City is facing major issues of the rational use of historic buildings and balancing the relationship between conservation and utilization. Therefore, the Palace Museum has conducted the indoor environmental monitoring for the Forbidden City since 2014, and a monitoring network has been established among 60 historic buildings to provide data support for the conservation of historic buildings in the Forbidden City.

\subsection{Monitoring Objectives}

To better control potential risks affecting the historic buildings of the Forbidden City, we make online collection for important parameters that can reflect the dynamic changes in the indoor environment of historic buildings. By linking those observations from the monitor network with and the current status of the preservation of historic buildings, we can find out the impact factors of various types of diseases, and then can investigate the deterioration mechanisms, analyze the threshold value of environmental factors, and find the balance point of various types of cultural relics. Eventually, the environmental parameters will guide the conservation management policies for preventive conservation, such as derive the optimal ventilating conditions and visitor volumes. 


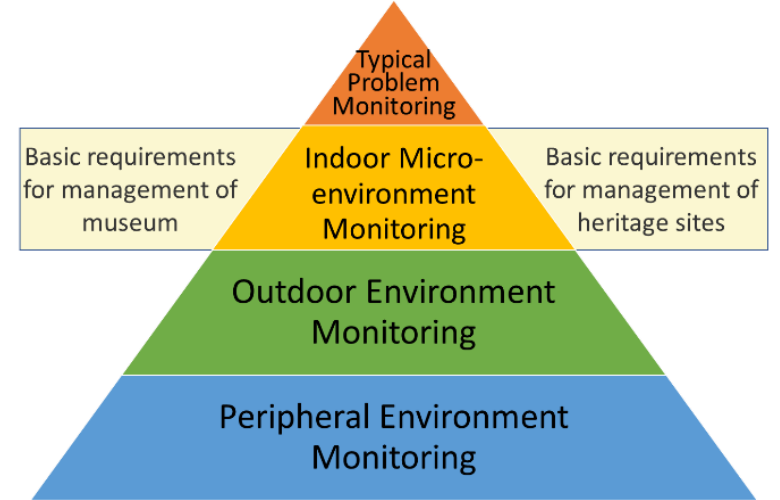

Figure 1. Environmental monitoring system of the Forbidden City

\section{METHORD}

\subsection{Monitoring Objects}

Among the 1087 historic buildings in the Forbidden City, of the most priority we need to grasp two balances: the balance between the different needs of heritage sites and museums; and the balance between immovable cultural heritage and movable cultural relics preservation environments. That is, we need to manage temperature, humidity, and pollutants positively in the exhibition halls of the museum to offer a well preservation environment for cultural relics in their collections (Wu, 2011); while the exhibition halls of the Forbidden City were transformed from historic buildings, which means the microenvironments had been changed from its natural state due to the modernization, making the historic buildings vulnerable new diseases. In addition, some of the exhibition halls in the Forbidden City are in the original state of display, decorated with many types of cultural relics, different types of cultural relics, cultural relics and historic buildings between the appropriate environment, the need to monitor their endowment environment to find the appropriate balance of the environment. Considering the above factors, the focus of indoor environmental monitoring in the Forbidden City is on modernized historic buildings and historic buildings with movable cultural relics.

\subsection{Monitoring Content}

Temperature and relative humidity are important environmental factors affecting historic buildings, and a hot and humid environment may lead to the growth of mold in painted mounts, accelerated rate of weathering of bricks, and other categories of heritage damage problems (Zhao, 2021). Indoor air pollution is also a critical issue in museum environments, where it not only represents a health hazard for visitors and workers, but also a risk for the conservation of the the relics (Krupińska, 2013) and historic buildings ( Grieken, 1998). Inhalation exposure to $\mathrm{CO}_{2}$ has been shown to have an effect on human health and psychomotor performance, and respiratory symptoms have been indicated in children exposed to indoor $\mathrm{CO}_{2}$ concentrations above $1000 \mathrm{ppm}$ (Azuma, 2018). Wood is generally used as the interior material in museum storage rooms. However, many museums have experienced deterioration of relics caused by VOCs in the wood due to acidification of the wood and the release of plywood or adhesives in it (Oikawa, 2005). Chemical reactions caused by light can weaken substances, change the color of dyes and pigments, and ultimately destroy them (Chen, 2002). There are different conclusions about the damaging properties of ultraviolet light versus visible light in different situations. However, it is very dangerous for both movable relics (Chen, 2002) and architectural paintings (Li, 2007).

Because of the above reasons, the Forbidden City indoor microenvironment monitoring using temperature and relative humidity as the basic parameters, for the needs of different situations of historic buildings, such as the historic buildings with extremely high visitor volumes, the exhibition halls which renovated recently, and the historic buildings with original state of furnishings affected by natural light, also selected $\mathrm{CO}_{2}$ concentration, total volatile organic compounds (TVOCs) concentration, illumination and ultraviolet intensity and other parameters as the main reference for monitoring the dynamic changes in the indoor environment.

\subsection{System Design Highlights}

\subsubsection{4-Hour Data Collection}

Due to the strict fire prevention requirements, the Forbidden City need to take daily three-level power failure management system. The power failure will cause the ordinary gateway to be unable to work and the data cannot be uploaded in time, which will cause intermittent interruption of monitoring work. For this reason, in the new technology development, we built backup strategies to deal with power supply shortages. When the external power supply is interrupted, the backup battery can provide more than 48 hours of working power, thus realizing the continuous upload of data in case of power failure. The wireless terminal equipment can meet the continuous working time of more than one year, and if the gateway is temporarily unable to carry out data forwarding, the monitoring terminal can store the data until the network is smooth and then upload the data.

\subsubsection{Stable data transmission}

The complex structure of the Forbidden City complex will cause a certain blockage to the wireless data communication signal of the equipment, resulting in unstable data transmission; the monitoring network topology changes frequently, and the interference of electronic devices of visitors in the open area will also lead to more frequent changes in wireless communication signal quality, affecting the stable transmission of data. Therefore, the Forbidden City indoor environment monitoring system uses a short-range wireless LAN based on IoT technology, monitoring terminals use short-range selforganizing network to automatically transmit data to the gateway device, uploaded by the gateway to the service platform. And the communication technology is constantly upgraded: now all from ZigBee communication technology is upgraded to LoRa wireless communication technology, and NB-IOT technology is tried in part of the no electricity palace group. The characteristics of each communication technology are shown in Table 1.

\subsubsection{Safety, Convenience and Contingency}

In order to protect the integrity of cultural heritage, the monitoring equipments are installed in non-destructive ways such as floating shelves, ties and high-strength magnet adsorption. The terminal equipments use small-capacity batteries with UL safety certification and explosion-proof safety design, which can operate stably in the ambient temperature range of $-55-85^{\circ} \mathrm{C}$ and meet the continuous working time of not less than one year to reduce the frequency of maintenance and thus avoid unnecessary damage to cultural relics.

To ensure that heritage managers can assess online monitoring data flexiably, whole providing a PC-based system for the indoor environmental monitoring network, a WeChat applet is developed to achieve 24-hour real-time query function to meet the demand for alarm processing for threshold exceedances, and can set different system access rights according to the work of 
different personnel, to facilitate the collaborative work of managers. and the data can be automatically recorded, so historical data can be obtained to analyse long-term influence ((Figure 2).

\begin{tabular}{|c|c|c|c|}
\hline & ZigBee & LoRa & NB-IoT \\
\hline Network Form & Low-Power LAN & Low-Power LAN & $\begin{array}{c}\text { Base Station-Based Cellular } \\
\text { Network }\end{array}$ \\
\hline $\begin{array}{l}\text { Network Deployment } \\
\text { Method }\end{array}$ & Terminal + Gateway & Terminal + Gateway & Terminal \\
\hline $\begin{array}{l}\text { Communication } \\
\text { Frequency Band }\end{array}$ & $2.4 \mathrm{GHz}$ & Sub $1 \mathrm{GHz}$ & Carrier Frequency Band \\
\hline Transmission Rate & $\begin{array}{l}250 \mathrm{kbps}, \text { Actual } \\
\text { About } 100 \mathrm{kbps}\end{array}$ & $0.3-50 \mathrm{kbps}$ & $\begin{array}{c}160-250 \mathrm{kbps} \text {, Actual About } \\
100 \mathrm{kbps}\end{array}$ \\
\hline $\begin{array}{l}\text { Communication } \\
\text { Distance }\end{array}$ & Near Distance (100 m) & Long Distance (2000 m) & Extra-Long Distance $(10 \mathrm{~km})$ \\
\hline Power Consumption & $\begin{array}{l}\text { Low Power } \\
\text { Consumption }\end{array}$ & $\begin{array}{l}\text { Ultra-Low Power } \\
\text { Consumption }\end{array}$ & Low Power Consumption \\
\hline
\end{tabular}

Table 1. Three types of communication technology characteristics

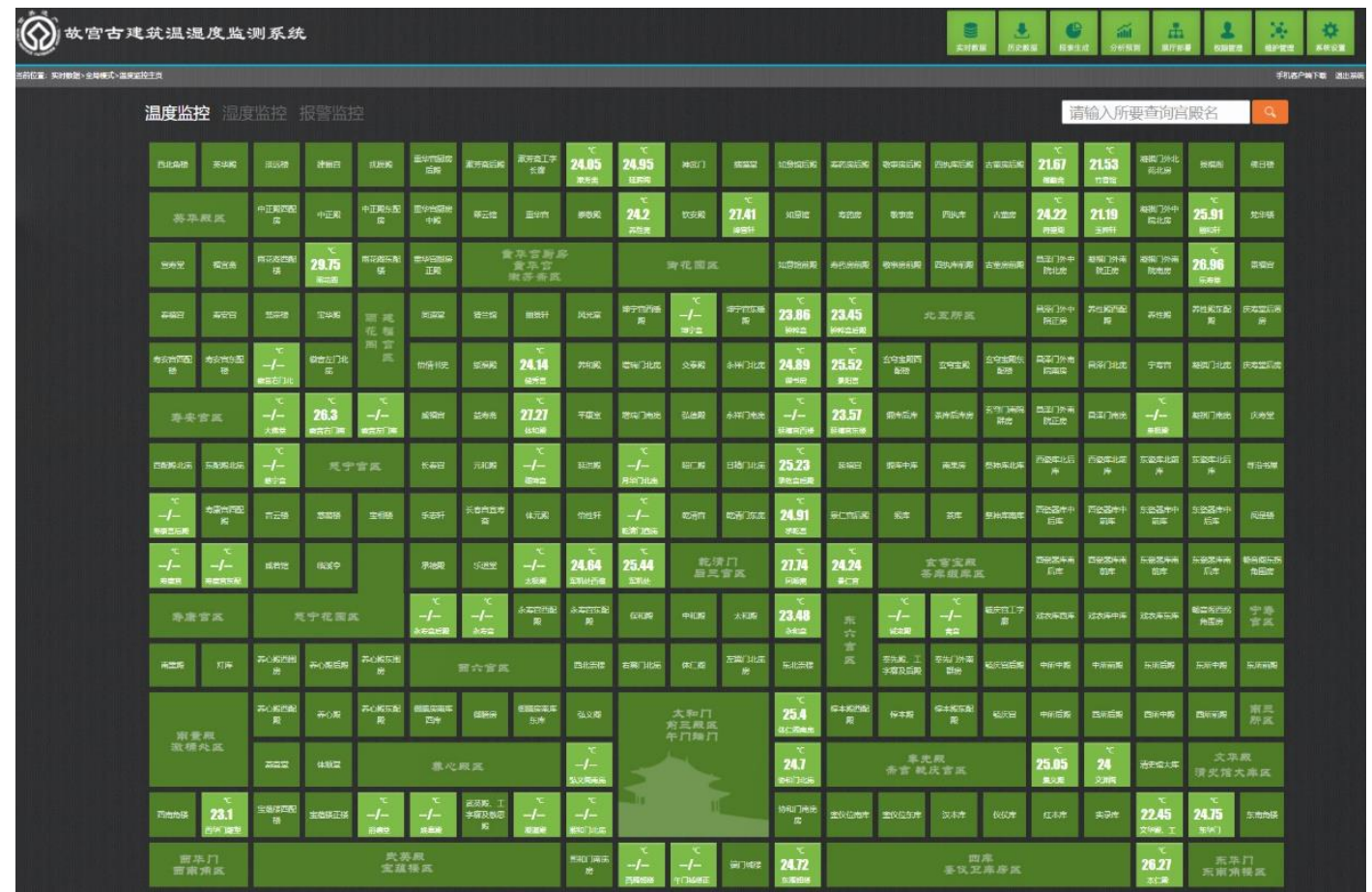

Figure 2. Real-time data of the indoor micro-environment monitoring system

\section{EXPERIMENTAL ENVIRONMENT AND RESULTS}

This section is divided into two parts. The first is an explanation of the background and the parameters used in the architectural experimental environment. The second is the results of our analysis of the exhibition microenvironment

\subsection{Experimental Background}

From $10^{\text {th }}$ Sept to $15^{\text {th }}$ Nov in 2020 , the Palace Museum held the exhibition " Everlasting Splendor: Six Centuries at the
Forbidden City" in the Meridian Gate. The exhibition hall consists of three parts: the West Yanchi Building, the main building of the Meridian Gate and the East Yanchi Building, equipped with constant temperature and relative humidity air conditioning system. In this paper, we select the East and West Yanchi Building with temperature,relative humidity and $\mathrm{CO}_{2}$ concentrations as the object of study, and use the indoor microenvironmental data of the historic buildings of the Forbidden City to evaluate the artificial environment regulation of the exhibition hall, and analyze the actual environment during the exhibition by combining the visitor volumes. 


\subsection{Experimental Results}

During the exhibition period, the temperature and relative humidity change curves of West Yanchi Building and East Yanchi Building are shown in Figure 3 and Figure 4. It shows that the two exhibition halls have similar change patterns: the temperature is relatively stable, basically fluctuating between $19-21^{\circ} \mathrm{C}$; the relative humidity is relatively stable at the beginning, maintaining around $50 \%$, and fluctuates more at the later stage, with an overall trend of slight decline, presumably related to seasonal changes; overall, both temperature and relative humidity can be divided into two stages: before the $1^{\text {st }}$ Oct, the two changes are consistent and extremely regular, while from the $1^{\text {st }}$ Oct, the fluctuation of the two began to intensify, and the original synchronous change pattern was broken, and an opposite trend of change appeared. Obviously, the $1^{\text {st }}$ Oct was the watershed day for the change of the visiting environment in the exhibition hall, and it was on this day that the number of visitors in the exhibition hall surged, increasing by $108 \%$ compared to the previous day, and maintaining a very high number of visitors until the end of the exhibition.

Therefore, it can be inferred that in the early stage of the exhibition, the exhibition hall under the regulation of constant temperature and relative humidity air conditioning system to maintain a relatively stable level. In the later period, when the visitor volumes surged, the indoor environment broke the original stable control, and the constant temperature and relative humidity state was slightly "out of control". As the temperature dropped during the exhibition, the demand for air conditioning in the exhibition hall increased, and the increase in temperature caused the relative humidity in the room to decrease. It should be noted that the temperature of the East Yanchi Building has been lowered several times, all between 8-9 a.m. on the opening day, which should be influenced by the cold air outside after the daily opening of the doors in late autumn.

According to the above analysis, it shows that the number of exhibition visitors brought a greater impact on the indoor temperature and relative humidity, so the daily visitor volumes was analyzed. During the exhibition period of " Everlasting Splendor: Six Centuries at the Forbidden City ", the single-day ticket sales volume was adjusted twice due to the alleviation of the Covid-19 epidemic: from $10^{\text {th }}$ Sept to $21^{\text {st }}$ Sept, the singleday ticket limit was 15,000 ; from $22^{\text {nd }}$ Sept to $30^{\text {th }}$ Sept, the single-day ticket limit was changed to 20,000 ; from $1^{\text {st }}$ Oct to November 15 , the single-day ticket limit was changed to 30,000 , and the daily tickets were sold out. The minimum visitor volumes was 4,000 on $17^{\text {th }} \mathrm{Sept}$, and the maximum number of visitors was 28,000 on $15^{\text {th }}$ Nov. Comparing the visitor volumes during the exhibition period with the maximum value of $\mathrm{CO}_{2}$ concentration on that day, it can be seen that there is an extremely strong correlation between the two (Figure 5). According to the Indoor Air Quality Standard (GB/T188832002 ), the standard value of $\mathrm{CO}_{2}$ concentration is $0.10 \%$, which is $1000 \mathrm{ppm}$, and it can be seen that the $\mathrm{CO}_{2}$ concentration exceeds the standard on more than half of the days during the exhibition period, up to $80 \%$, which has a negative impact on the human health of visitors and staffs as well as the historic buildings, and it is necessary to improve the management of the exhibition, such as starting to restrict the visitor volumes. It is necessary to improve the management of the exhibition halls, such as starting to restrict the visitor volumes and other measures, such as install fresh air equipment in the exhibition halls with weak ventilation.

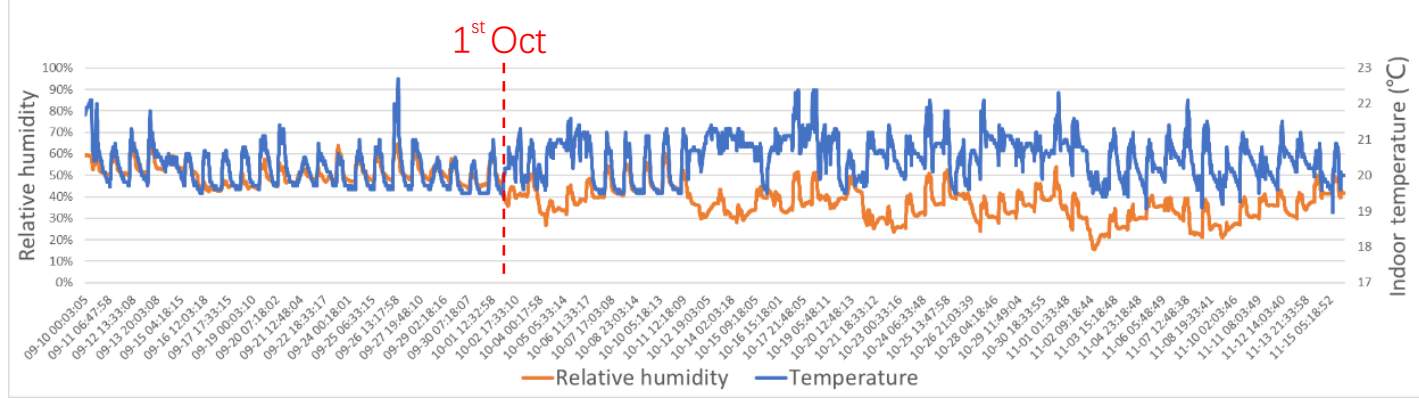

Figure 3. Temperature and relative humidity change curve of West Yanchi Building during the exhibition

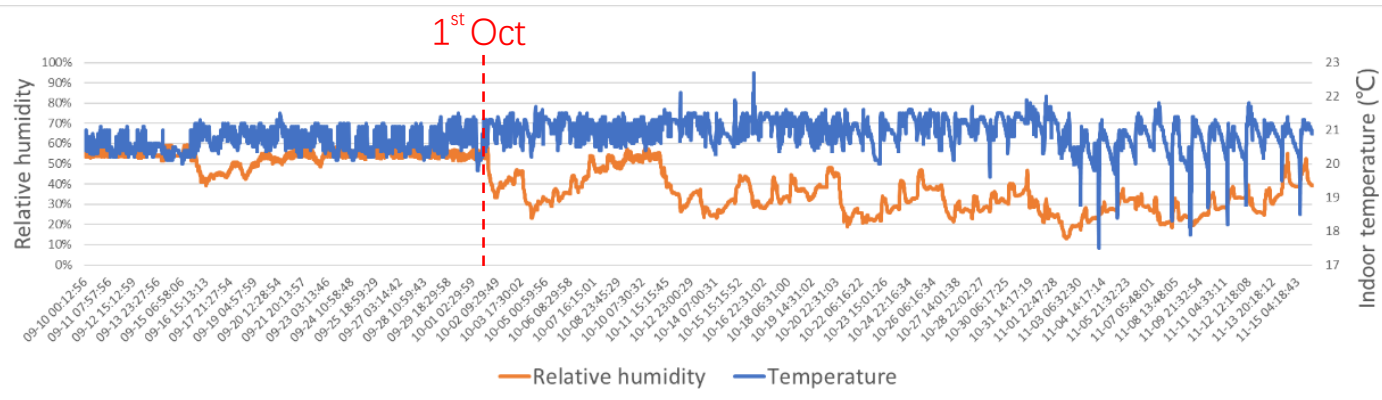

Figure 4. Temperature and relative humidity change curve of East Yanchi Building during the exhibition 


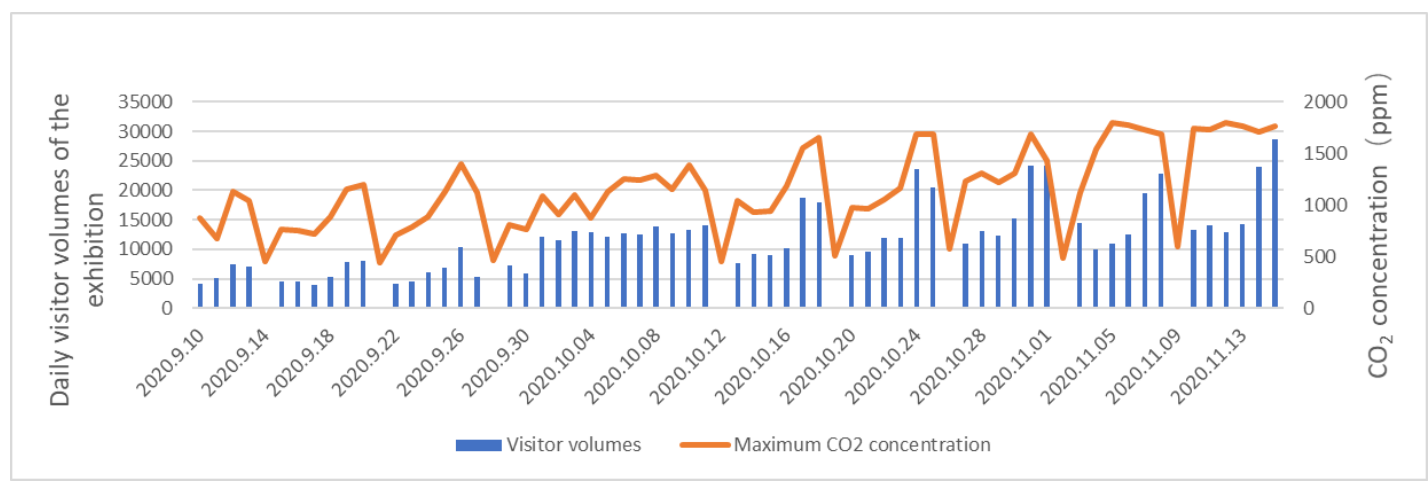

Figure 5. Comparison of visitor volumes and $\mathrm{CO}_{2}$ concentration during the development period

The control of $\mathrm{CO}_{2}$ concentrations and constant temperature and relative humidity in the exhibition hall reflect the impact of visitor volumes on the microenvironment of historic buildings, which should be taken seriously and studied for improvement. This case shows the importance of monitoring and analysis of the indoor micro-environment of historic buildings, which can help managers to identify weaknesses in the exhibition or in the historic buildings themselves in advance and provide scientific data support for management decisions, which is of great significance for the preventive conservation of historic buildings in heritage sites.

\section{CONCLUSIONS AND FUTURE WORK}

This research uses the case of exhibition in the Meridian Gate to initially reflect the effect of audience flow on the indoor microenvironment by analyzing the monitoring data of indoor temperature, relative humidity and $\mathrm{CO}_{2}$ concentration. It shows that too many visitors to the exhibition hall micro-environment has a very negative impact. On the one hand, the constant temperature and humidity in the exhibition hall can be slightly out of control, increasing the risk of deterioration of cultural relics and heritage buildings. And on the other hand, in poorly ventilated exhibition halls, visitors exhaled $\mathrm{CO}_{2}$ is not easily diffused, which can make the indoor $\mathrm{CO}_{2}$ concentration exceed the health threshold, threatening the health and safety of visitors and staffs. Therefore, it is necessary to manage the visitor volumes to heritage sites scientifically and install fresh air equipment in the exhibition halls with weak ventilation.

The indoor micro-environment monitoring system of the Forbidden City has been working steadily and has accumulated a large amount of historical monitoring data for seven years since its operation. but it has also revealed the problem of weak use of monitoring data, lack of in-depth study of the data, and has not yet formed a systematic theory to guide the development of conservation management. Therefore, in the follow-up work, we will focus on the following points.

1. Strengthen the use of historical data to quantify the relationship between the level of deterioration of historic buildings and environmental parameters, thus helping to predict the emergence of disease and provide strong support for preventive protection.

2. Select appropriate communication technologies for the monitoring requirements of different palaces, increase the number of historic buildings monitored, and appropriately increase the monitoring parameters to strengthen multi-factor correlation analysis.

3. According to the analysis results of the above study, build the technical guidelines for monitoring the deterioration of historic buildings and guide the development of management system, and gradually form a set of systematic and perfect monitoring management system.

\section{ACKNOWLEDGEMENTS}

This study was supported by the National Key R\&D Program of China (Grant No. 2019YFC1520900).

\section{REFERENCES}

Azuma, K., Kagi, N., Yanagi, U., 2018. Effects of low-level inhalation exposure to carbon dioxide in indoor environments: A short review on human health and psychomotor performance. Environment International, 121:51-56. https://doi.org/10.1016/ j.envint.2018.08.059

Chen, Y.S., 2002. Studies on museum environmental standards. Sciences of Conservation and Archaeology. 14: 153-191. (in Chinese)

Grieken, R. V., Delalieux, F., Gysels, K., 1998. Cultural heritage and the environment. Pure and Applied Chemistry, 70(12), 2327 2331 .

Indoor Air Quality Standard (GB/T18883-2002)

Krupińska, B., Van Grieken, R., De Wael, K., 2013. Air quality monitoring in a museum for preventive conservation: Results of a three-year study in the Plantin-Moretus Museum in Antwerp, Belgium. Microchem. 110, 350-360.

Li., Z.J., Ma. J., 2007. The study of ultra violate's impact on paints and colored drawings of Classical Chinese architecture. 023(009), 41-43.

Oikawa, T., Matsui, T., Matsuda, Y., Takayama, T. , Niinuma, H., \& Nishida, Y. , et al., 2005. Volatile organic compounds from wood and their influences on museum artifact materials i. differences in wood species and analyses of causal substances of deterioration. Journal of Wood Science, 51(4), 363-369.

Wu, L.M., Xu, F.Y., Huang, H., 2011. The demand analysis of museum environment monitoring and the application of internet of things. Sciences of Conservation and Archaeology, 23(3), 96102. (in Chinese)

Zhao, F., 2021. Research on the hygrothermal environment of the middle hall building of Longju Temple, Guanghan. Sciences of Conservation and Archaeology, 33(1), 110-117. (in Chinese) 